\title{
Nanogram per Milliliter per Milligram per Meter Squared per Day
}

National Cancer Institute

\section{Source}

National Cancer Institute. Nanogram per Milliliter per Milligram per Meter Squared per

Day. NCI Thesaurus. Code C119447.

A unit of concentration equal to nanograms per milliliter, divided by milligrams per meter squared per day. 